\author{
\begin{tabular}{l|l} 
Е.П. Макаров & E.P. Makarov
\end{tabular} \\ Экономическая демография \\ колониальной эпохи

\section{Economic Demography of the Colonial Era of North America} Северной Америки

DOI: $10.31518 / 2618-9100-2019-4-1$

УДК 94(410).07

Выходные данные для цитирования:

Макаров Е.П. Экономическая демография колониальной эпохи Северной Америки // Исторический курьер. 2019. № 4 (6). Статья 1. URL: http://istkurier.ru/data/2019/ISTKURIER-2019-4-01.pdf

\author{
DOI: 10.31518/2618-9100-2019-4-1
}

\section{How to cite:}

Makarov E.P. Economic Demography of the Colonial Era of North America // Historical Courier, 2019, \# 4 (6). Article 1. [Available online:] http://istkurier.ru/data/2019/ISTKURIER-2019-401.pdf

\begin{abstract}
The first British settlements in America were founded in 1607, almost 170 years before the signing of the declarations of US independence. As usual, it is believed that the need for labor resources and capital in the new land, and as a result in our economy, allowed the white population to quickly achieve a high standard of living. However, over time, the colonial life did not show a significant improvement in the quality of life of the settlers. The resource abundance factor plays an important role in the formation of colonial institutions, encourages the white population to strive for the development of production, is based on slave labor and the formation of local governments. Most colonists are satisfied with the form of relations with the metropolis, but after 1763 changes in colonial policy led to increased tensions in the relationship between the colony and the UK. The article is devoted to the economic demography of the North American colonies, which in 1776 became the United States. During the $17^{\text {th }}-18^{\text {th }}$ centuries. Britain established the largest number of colonies in North and South America, including parts of the Canadian coast and West Indies. In the same period, other European states were also involved in the process of colonization of North America. The Spain founded settlements in southwestern Florida, France mastered Quebec, and until the 1660s. The Netherlands controlled areas that would later become part of the states of New York and New Jersey. Focusing on the process of European colonization of the region leaves aside the experience of indigenous peoples who had mastered North America for thousands of years before the arrival of European pioneers. For these groups, European colonization turned out to be a destructive process. Outbreaks of European diseases, such as smallpox, quickly destroyed the local population, and the diseases themselves were brought to the continent from the time of European fishing expeditions, even before permanent settlements of Europeans were founded. When the Europeans began to establish the first settlements, they encountered the native inhabitants of these places, and the constant influx of colonists found less and less resistance, which allowed them to occupy territories liberated by Indian tribes retreating deep into the continent.
\end{abstract}

Keywords: USA; American colonies; colonial economy; colonial demography.

The article has been received by the editor on 10.07.2019.

Full text of the article in Russian and references in English are available below.

\footnotetext{
* Макаров Егор Павлович, канд. ист. наук, старший преподаватель кафедры социологии, политологии и истории Отечества, Институт социально-гуманитарных наук и технологий, Самарский государственный технический университет (Самара, Россия), e-mail: egor.makarov.esq@gmail.com

Makarov Egor Pavlovich, Candidate of Historical Sciences, Senior Lecturer at the Department of Sociology, Political Science and History of the Fatherland, Institute of Social Sciences and Technologies, Samara State Technical University, (Samara, Russia), e-mail: egor.makarov.esq@gmail.com
} 
Аннотация. Первые британские поселения в Америке, которые позже станут фундаментом государства Соединенных штатов, были основаны в 1607 г., почти за 170 лет до подписания декларации независимости США. Как традиционно считается, обилие природных ресурсов, спрос на рабочие руки и капитал способствовали притоку населения в новые земли, и как следствие быстрому росту экономики колоний, который в свою очередь, позволил белому населению достаточно быстро достичь высокого уровня жизни. Однако со временем, колониальный быт не показал значительного улучшения качества жизни поселенцев. Фактор изобилия ресурсов сыграл важную роль в формировании колониальных институтов, поощряя белое население в стремлении к развитию производств, основанных на рабском труде, и формированию местных правительств. Большинство колонистов устраивала форма взаимоотношений с метрополией, однако после 1763 г. изменения колониальной политики существенно повысили напряженность во взаимоотношении колоний и Великобритании, что в конечном счете привело к объявлению местным населением собственной независимости. Статья посвящена экономической демографии североамериканских колоний, которые в 1776 г. стали соединенными штатами. В течение XVII-XVIII вв. Великобритания основала самое большое число колоний в Северной и Южной Америке, включая части канадского побережья и Вест-Индии. В тот же период, другие европейские государства также были вовлечены в процесс колонизации Северной Америки. Испанцы основали поселения на юго-западе Флориды, Франция осваивала Квебек, и до 1660-х гг. Нидерланды контролировали области, которые позднее войдут в состав штатов Нью-Йорк и Нью-Джерси. Сосредоточение внимания на процессе европейской колонизации региона, оставляет в стороне опыт коренных народов, осваивавших территории Северной Америки в течение тысячелетий до прибытия европейских первопроходцев. Для данных групп, европейская колонизация оказалась разрушительным процессом. Вспышки европейских болезней, таких как оспа, быстро уничтожали местное население, при этом сами болезни были занесены на континент со времен европейских промысловых экспедиций, еще до того, как были основаны постоянные поселения европейцев. Когда европейцы начали основывать первые поселения, они сталкивались с коренными обитателями этих мест, а постоянный приток колонистов находил все меньшее сопротивление, что позволяло занимать территории, освобожденные отступающими вглубь континента индейскими племенами.

Ключевые слова: США; американские колонии; колониальная экономика; колониальная демография.

$$
* * *
$$

В большинстве современных работ, история колониальной стадии развития американской экономики, традиционно рассматривается в качестве фона для последующего развития экономики США. Акцент при этом, часто делается на то, как события, предшествующие провозглашению независимости от Великобритании, формировали последовательную эволюцию экономики Соединенных штатов. Оценивая экономические показатели и уровень доходов колониального периода стоит признать, что имеющиеся по этому вопросу статистические данные, крайне ограничены. Современные исследования берут за основу показатели уровня жизни, которые демонстрировали свободные белые колонисты, и сопоставляют их с уровнем жизни британцев, имевших в тот период один из самых высоких в мире доходов на душу населения. Ученые собрали данные по оплате труда неквалифицированной рабочей силы и стоимости жилья для рабочих в трех британских колониях Северной Америки: Пенсильвании, Массачусетс и Мэриленд, а также городах Европы, таких как Лондон, поэтому можно сравнить уровень благосостояния жителей этих мест.

Ко времени начала американских революционных процессов, рабочие Филадельфии имели самый высокий заработок, примерно на 25 \% выше, чем средний заработок рабочего в 
Лондоне. Рабочие Бостона и Балтимора, при этом, незначительно отставали по уровню заработка от лондонских трудящихся. Имеются сравнительные оценки трудовых и имущественных доходов, что позволяет выстроить совокупные данные по доходам на душу населения к середине 1770-х гг., и изучить распределение доходов на территории колоний. В современных исследованиях показано, что в обозначенный период, доходы на душу населения были выше именно в американских колониях, нежели в Великобритании, и распределялись более равномерно. Средний коэффициент Джини, показывающий степень расслоения общества, и использующийся для оценок экономического неравенства, для свободного американского колониста составлял 0,4. При этом подобный показатель для стран Северной Европы в среднем составлял 0,57. Примечательно, что даже с учетом несвободного населения, коэффициент Джини для Североамериканских колоний в среднем составлял 0,44 , что также ниже европейского показателя ${ }^{1}$.

Демографические данные свидетельствуют о том, что отправной точкой для исследования колониальной экономики можно считать 1607 г., основание Джеймстауна в Виргинии. К тому времени, как американские колонии провозгласили собственную независимость в 1776 г., население колониальной Америки выросло с нескольких сотен до двух с половиной миллионов человек. Однако даже это население было ограничено полосой земли вдоль побережья Атлантики, от Джорджии на юге, до Мэн на севере. Рост числа поселенцев из Европы и африканских рабов сопровождался сокращением численности коренного населения. Исследования на данную тему сообщают, что туземное население в области к востоку от Миссисипи сократилось примерно с 500000 человек в 1600 г. до 250000 к 1700 г., а к 1800 г. достигло показателя в 170000 человек. Опираясь на данные переписей, налоговые ведомости и иную документацию, историкам, специализирующимся на демографических вопросах удалось составить достаточно подробные оценки роста белого, и не белого населения Америки ${ }^{2}$.Высокий уровень рождаемости, практика ранних браков и относительно небольшое число одиноких, в целом давали быстрые темпы естественного роста населения колоний. Добровольная миграция из Европы, и ввоз рабов еще сильнее увеличивали темпы роста населения, составляя в среднем прирост примерно в $2,8 \%$ в год, на протяжении большей части колониального периода. Этот показатель сам по себе уже был достаточным для того, чтобы обеспечить удвоение населения каждого поколения американских поселенцев. Темпы роста в первые десятилетия колонизации показывали наивысшие значения, поскольку высокий приток иммигрантов совпадал с невысоким числом поселенцев на местах. В последующие периоды темпы прироста замедлились, поскольку естественный прирост стал главным фактором увеличения населения колоний ${ }^{3}$.

Территории Новой Англии составляли практически все колониальное население до конца XVII в., однако после 1680 г., можно фиксировать приток населения в области центральной Атлантики: Нью-Йорк, Нью-Джерси и Пенсильванию. С 1700 г. рост числа мигрантов позволил существенно укрупниться поселениям Каролины и Джорджии, хотя они долгое время были существенно меньше заселены в сравнении с населенными пунктами северных штатов. Первые колонисты испытывали значительные неудобства, будучи вынужденными приспосабливаться к новым климатическим условиям, болезням и особенностям окружающей среды. Первоначально высокие показатели смертности со временем снизились, что было связано с улучшением бытовых условий проживания и общего качества жизни. Принимая во внимание устойчивый рост колониального населения при диверсифицированной экономике, ученые полагают, что доход на душу населения в

\footnotetext{
${ }^{1}$ Bjork G.C. The Weaning of the American Economy: Independence, Market Changes, and Economic Development // Journal of Economic History. 1964. № 24 (4). P. 541-560.

${ }^{2}$ Jones A.H. Wealth of a Nation to Be: The American Colonies on the Eve of the Revolution. New York, 1980.

${ }^{3}$ Lindert P.H., Williamson J.G. American Colonial Incomes, 1650-1774 // Economic History Review. 2016. № 69 (1). P. 54-77.
} 
колониальный период должен был неуклонно расти. В исследовании ${ }^{4}$ Д. МакКаскера и P. Менарда отражено, что в колониях, доходы на душу населения за XVIII в. росли также быстро, как в Великобритании, и даже возможно почти вдвое быстрее. Предполагалось, что рост доходов составлял 0,3-0,6 \% в год. Более поздние исследования П. Мэнколла и Т. Уейса показывают, что совокупный экономический рост в колониях был довольно небольшим. Проанализировав данные о потреблении пищи различными слоями населения, а также экспортные показатели, ученые выявили статистику уровня потребления сельскохозяйственной продукции на душу населения с течением времени. Были получены данные о том, что доход на душу населения повысился с 64 долларов в 1700 г. до 68 долларов в 1770 г., а затем упал до 67 долларов в 1800 г. Таким образом темпы роста ВВП составили всего 0,04 процента за весь XVIII в. ${ }^{5}$ Несмотря на то, что работы П. Мэнколла и Т. Уейса не давали исчерпывающей информации об объемах сельскохозяйственного производства, их оценки ВВП основывались на вероятных значениях внутреннего сельскохозяйственного потребления. Даже если учесть, что темпы роста сельскохозяйственного производства помогут получить данные о ВВП на душу населения, к первой половине XIX в. рост доходов составил бы 0,2 \% в год, а этот показатель еще меньше того, что давался Д. МакКаскером и Р. Менардом. В исследовании П. Линдерта и Д. Уильямсона также обосновывается мнение о том, что в течение всего XVIII в. экономический рост был медленным, а рост доходов составлял бы $0,2-0,3 \%$ в год ${ }^{6}$.

Одним из важнейших источников информации о реальном уровне благосостояния населения колоний являются документы о завещании имущества. Э. Джонс ${ }^{7}$ в своем исследовании проводит анализ 900 документов 1774 г. из случайно выбранных округов каждой из колоний. По итогам работы было выявлено, что существует большой разрыв в накоплении богатств между колониальными регионами. Жители Южных колоний накопили в два рада больше богатства, чем жители Средней Атлантики, и в два с половиной раза больше, чем жители Новой Англии. Разница при этом, отражает влияние использования рабского труда и работорговли на распределение богатства. При этом, если учитывать владение богатством небелого населения, то показатели различных регионов североамериканских колоний фактически выравниваются. Из данного обстоятельства можно сделать вывод о том, что рабовладение позволило белому населению южных колоний сконцентрировать в своих руках большие финансовые средства, источником которых был труд невольников. При этом если не брать в расчет капиталы, связанные с рабским трудом, процесс накопления капитала был схожим в колониях независимо от региона.

Еще одним примером оценок благосостояния колониального населения является исследование эволюции стоимости недвижимости, предпринятая Г. Майн и Д. Майн, в хронологическом диапазоне $1640-1774$ гг. ${ }^{8}$ В работе были проанализированы цены на более чем 16000 объектов недвижимости Новой Англии и сделан вывод о том, что благосостояние жителей северных колоний во многом было связано с недвижимостью и землевладением. При постоянном росте цен на землю и жилье, стоимость других категорий благосостояния американских колонистов, со временем снижалась, кратковременно повышаясь лишь в периоды массового размежевания новых земель и благоустройства вновь создаваемых

\footnotetext{
${ }^{4}$ McCusker J., Menard R. The Economy of British America, 1607-1789. Chapel Hill, NC., 1985.

${ }^{5}$ Mancall P.C., Weiss T. Was Economic Growth Likely in Colonial British North America? // Journal of Economic History. 1999. № 59 (1). P. 17-40.

Mancall P.C., Rosenbloom J.L., Weiss T. Slave Prices and the South Carolina Economy, 1722 to $1800 / /$ Journal of Economic History. 2001. № 61 (3). P. 616-639.

${ }^{6}$ Lindert P.H., Williamson J.G. American Incomes Before and After the Revolution // Journal of Economic History, 2013, № 73 (3). P. 725-765; Lindert P.H., Williamson J.G. Unequal Gains: American Growth and Inequality since 1700. Princeton, 2016.

${ }^{7}$ Jones A.H. Wealth of a Nation to Be: The American Colonies on the Eve of the Revolution. New York, 1980.

${ }^{8}$ Main G.L., Main J.T. Economic Growth and the Standard of Living in Southern New England, 1640-1774 // Journal of Economic History. 1988. № 48 (3). P. 27-46.
} 
домохозяйств. Сопоставление данных исследований показывает достаточно статичную картину экономического развития колониальных территорий, из которой выделяются фермерские хозяйства постепенно заселенных внутренних территорий, которые медленно накапливали богатства, в основном концентрировавшиеся в покупке и продаже крупного и мелкого рогатого скота. Специальное исследование, посвященное штату Пенсильвания показывает изменение производительности сельского хозяйства на всем протяжении XVIII в. Учитывая приросты на зерновых фермах и скотоводческих хозяйствах, а также стоимость земли и труда, было выявлено, что в период 1750-1770 гг. производительная способность выросла на 8 \% по сравнению с периодом 1714-1730 гг., однако к периоду 1775-1790 гг. рост производительности замедлился и составил лишь $5 \%$.

Колониальная экономика традиционно рассматривается в соотношении больших объемов земли и природных ресурсов с потребностью в высоких трудозатратах. Согласно демографической модели, обилие природных ресурсов повышало производительность труда, в особенности в сельском хозяйстве, способствуя повышению уровня жизни колонистов и устранению демографических ограничений, которым были подвержены европейские производители. Непрерывный естественный прирост населения, в совокупности с добровольной и вынужденной миграцией, способствовал быстрому экстенсивному росту экономики. Также, при взгляде на колониальную экономику важно влияние, которое оказывают основные экспортные товары. Объемы экспорта риса, табака, кофе, хлопка были фактором, во многом определяющим размер и структуру колониальной экономики ${ }^{10}$. Из-за доступности невозделанной земли приобщение к занятию сельским хозяйством поощрялось колониальными властями, а само семейное фермерство способствовало раннему браку и высоким показателям рождаемости. В то же время смертность оставалась на низком уровне из-за обилия и разнообразия пищи, в то время как низкая плотность населения препятствовала распространению болезней. Исходя из этого, в количественных показателях экономического производства продовольствия доминировало внутреннее, в основном местное потребление. Исследователи подсчитали, что за весь XVIII в. экспорт продовольствия затрагивал не более чем $10 \%$ от общего числа производимых продуктов питания ${ }^{11}$. Даже в ориентированных на экспортное производство южных колониях, внешняя торговля составляла только 20-25\% ВВП и показывала тенденцию к снижению на всем протяжении XVIII в. Тем не менее, стоит признать, что экспорт был элементом, необходимым для экономического выживания колоний. С одной стороны приобщение к колониальному экспорту в международной имперской торговле Великобритании было важной причиной самого процесса колонизации ${ }^{12}$. С другой стороны, полученные от экспорта доходы определяли платежную способность колоний и их возможности оплачивать промышленные товары из метрополии, которые не могли быть произведены в самих колониях. Различия в экспортных культурах привели к появлению особых экономических структур в колониях, что отражалось на распределении богатств ${ }^{13}$. Валотильность в международной торговле, в свою очередь, сыграла важную роль в содействии краткосрочных периодов роста колониальной экономики, однако экономические эффекты, затрагивающие портовые города, не сильно влияли на фермерские хозяйства, расположенные вдали от центров торговли и ориентированные прежде всего на внутренние районы.

Климатические условия южных колоний способствовали выращиванию культур,

\footnotetext{
${ }^{9}$ Acemoglu D., Johnson S., Robinson J. Reversal of Fortune: Geography and Institutions in the Making of the Modern World Income Distribution // Quarterly Journal of Economics. 2002. № 117 (4). P. 1231-1294.

${ }^{10}$ West R. C. Money in the Colonial American Economy // Economic Inquiry. 1978. № 16. P. 1-15.

${ }^{11}$ Bjork G.C. The Weaning of the American Economy: Independence, Market Changes, and Economic Development // Journal of Economic History. 1964. № 24 (4). P. 541-560.

${ }^{12}$ Weiss R. The Issue of Paper Money in the American Colonies, 1720-1774 // Journal of Economic History. 1970. № 30. P. 770-785.

${ }^{13}$ Main G.L., Main J.T. Economic Growth and the Standard of Living in Southern New England, 1640-1774// Journal of Economic History. 1988. № 48 (3). P. 27-46.
} 
нашедших прибыльные рынки сбыта в Европе. К примеру в Виргинии, Северной Каролине и Мэриленде распространилось выращивание табака, что сразу отразилось на экономике сопредельных штатов, поскольку стимулировало спрос на рабочую силу и регулировало потоки трудовой миграции. Табачные плантации не требовали крупных капиталовложений, и поначалу занимали незначительное место в колониальной экономике. При этом, в производстве и торговле табаком доминировали мелкие землевладельцы, часто выращивающие продукт на собственной земле силами одной фермерской династии, редко нанимавшей поденных рабочих ${ }^{14}$. K началу XVIII в. плантаторы южных колоний начали активно использовать рабский труд, что сразу же сказалось на расширении многих сельскохозяйственных производств. Население более южных колоний, таких как Южная Каролина и Джорджия, приспособили местные условия для выращивания риса, отдавая ему предпочтение перед табаком ${ }^{15}$. Существенным отличием было то, что сельскохозяйственное производство риса было основано на крупных капиталовложениях, в основном необходимых для обеспечения и поддержания необходимого уровня орошения посадок. Рис выращивался на крупных плантациях, при этом многие поля затоплялись или осушались, а непрерывность цикла сельскохозяйственного производства обеспечивал рабский труд ${ }^{16}$.

Климат северных колоний напоминал условия Западной Европы, ограничивая экспортные возможности Пенсильвании, Нью-Джерси и Нью-Йорка. Тем не менее, в этих областях успешно развивались хозяйства, специализировавшиеся на животноводстве, выращивании пшеницы и других зерновых культур, а экспорт в основном, осуществлялся в Вест-Индию. Условия региона Новой Англии не благоприятствовали накоплению излишков продукции, однако северные регионы имели достаточно активные, склонные к кооперации торговые сообщества, которые помогали в организации и развитии региональной и международной торговли. Обладая развитой транспортной инфраструктурой, города Новой Англии быстро росли, в частности к 1775 г. в Филадельфии проживало около 30000 жителей, в Нью-Йорке 25 000, в Бостоне 16000 человек ${ }^{17}$. Сравнительно с этим, в крупнейшем городе южных колоний Чарльстоне к тому времени проживало не более 12000 человек ${ }^{18}$.

Региональные различия в производстве товаров и их экспорте тесно связаны с вопросом использования рабского труда. Несмотря на то, что рабство было законным на всей территории североамериканских колоний, к началу 1770-х гг. более $90 \%$ всех рабов было сосредоточено на территориях от Мэриленда до Джорджии. Исследователи часто объясняют неравномерное использование рабского труда ориентацией производств на различные сельскохозяйственные культуры. Так, обозначенные различия в выращивании риса и табака хорошо демонстрируют аргументы данного подхода. Трудозатраты были тесным образом связаны с масштабом производства. К примеру, орошение рисовых полей ориентировало производителей на крупномасштабное производство, в то время как табак был пригоден для выращивания и в малых фермерских хозяйствах ${ }^{19}$.

При наличии основного фермерского хозяйства и сопредельной невозделанной земли расширение собственного семейного хозяйства не было сложным предприятием. Поэтому семейный бизнес, расширяющий масштабы сельскохозяйственного производства, неизбежно сталкивался с привлечением дополнительной рабочей силы. Наличие возможности к привлечению труда невольников создавало перспективы быстрого расширения производства

\footnotetext{
${ }^{14}$ Bjork G.C. The Weaning of the American Economy: Independence, Market Changes, and Economic Development // Journal of Economic History. 1964. № 24 (4). P. 541-560.

${ }^{15}$ Acemoglu D., Johnson S., Robinson J. Reversal of Fortune: Geography and Institutions in the Making of the Modern World Income Distribution // Quarterly Journal of Economics .2002. № 117 (4). P. 1231-1294.

${ }^{16}$ Galenson D. The Rise and Fall of Indentured Servitude in the Americas: An Economic Analysis // Journal of Economic History. 1984. № 44 (1). P. 1-26.

${ }^{17}$ Jones A.H. Wealth of a Nation to Be: The American Colonies on the Eve of the Revolution. New York, 1980.

${ }^{18}$ Morgan E.S. The Labor Problem at Jamestown, 1607-1618 // American Historical Review. 1971. № 76 (3). P. $595-611$.

${ }^{19}$ Rosenbloom J.L., Weiss T. Economic Growth in the Mid Atlantic Region: Conjectural Estimates for 1720 to $1800 / /$ Explorations in Economic History. 2014. № 51 (1). P. 41-59.
} 
при относительно небольших вложениях, a стоимость экспортируемых сельскохозяйственных культур быстро покрывала расходы на приобретение рабов. Но были и противоположные тенденции. В периоды расширения производств табака в Виргинии, Северной Каролине и Мэриленде, цены на рабов были достаточно высоки, что объяснялось высоким спросом на несвободную рабочую силу на сахарных плантациях Вест-Индии. Поэтому плантаторы, стремившиеся к расширению производств во многом полагались на европейскую трудовую миграцию ${ }^{20}$. Такой миграции способствовали перспективы стабильного и высокого заработка в Америке. В то же время ее сдерживала высокая стоимость путешествия через Атлантику, которая составляла до полугодового дохода наемного работника. Это обстоятельство породило практику, согласно которой многие работники прибывали в Америку как наемные слуги, заключившие договор, по которому путешествие в колонии компенсировалось их работой на протяжении определенного срока, в среднем до 3-4 лет. Как только они прибывали в колонии, подобных договор продавался плантаторам, которые стремились привлечь дополнительную рабочую силу' ${ }^{21}$. После окончания срока действия договора наемный работник получал небольшую фиксированную выплату, которой, как правило, хватало на покупку земли и основание своего собственного фермерского хозяйства. Менее распространенной была практика, согласно которой европеец заключал с капитаном корабля договор о том, что по прибытии он будет продан в рабство, и полученная сумма покроет транспортные расходы ${ }^{22}$.

Данные по иммиграции колониального периода заставляют некоторых исследователей предполагать, что большинство прибывших в американские колонии европейцев заключали подобные договоры. Ф. Грабб, в частности, в своей работе подсчитал, что три четверти британских иммигрантов и три пятых немецких иммигрантов прибыли в Пенсильванию именно в качестве наемных работников по договору ${ }^{23}$. Уместно также привести доводы Д. Галенсона, считавшего, что спрос на подобную договорную рабочую силу, а также продолжительность службы зависели от периодов расширения крупных сельскохозяйственных производств и соответствующей необходимости пополнения хозяйств как неквалифицированной, так и квалифицированной рабочей силой ${ }^{24}$. Если взять для рассмотрения период 1680-х гг., то можно заметить, что плантаторы Виргинии, Северной Каролины и Мэриленда начали отходить от практики покупки договора наемного работника и в большей степени полагались на труд африканских рабов. Д. Галенсон объясняет это обстоятельство тем, что совпали два процесса: снижение цен на рынке рабов, и стабилизация британского рынка труда, с последующим ростом стоимости рабочих рук европейцев ${ }^{25}$.

В период постепенного снижения спроса на договоры наемных работников, они продолжали покупаться плантаторами там, где был необходим квалифицированный труд. С начала 1700-х гг. большинство наемных работников предпочитало мигрировать в среднеатлантический регион, а плантации стали прочно ассоциироваться с использованием рабского труда ${ }^{26}$.Если взять пример Южной Каролины, можно заметить, что плантаторы этой колонии, развивая рисовые производства, с 1690-х годов полагались на рабский труд ${ }^{27}$. Связь

\footnotetext{
${ }^{20}$ Weiss $T$. Review of Unequaly Gains: American Growth and Inequality since 1700, by Peter H. Lindert and Jeffry G. Williamson // Journal of Economic History. 2017. № 77 (3). P. 952-954.

${ }^{21}$ Galenson D. White Servitude in Colonial America: An Economic Analysis. Cambridge, 1981.

${ }^{22}$ Egnal M. New World Economies: The Growth of the Thirteen Colonies and Early Canada. New York, 1998.

${ }^{23}$ Grubb F. Redemptioner Immigration to Pennsylvania: Evidence on Contract Choice and Profitability // Journal of Economic History. 1986. № 46 (2). P. 407-418.

${ }^{24}$ Allen R., Murphy T., Schneider E. The Colonial Origins of the Divergence in the Americas: A Labor Market Approach // Journal of Economic History. 2012. № 72 (4). P. 863-894.

${ }^{25}$ Galenson D. The Rise and Fall of Indentured Servitude in the Americas: An Economic Analysis // Journal of Economic History. 1984. № 44 (1). P. 1-26.

${ }^{26}$ Mancall P.C., Weiss T. Was Economic Growth Likely in Colonial British North America? // Journal of Economic History. 1999. № 59 (1). P. 17-40.

${ }^{27}$ Grubb F. The Incidence of Servitude in Trans-Atlantic Migration, 1771-1804 // Explorations in Economic History.
} 
ориентированного на экспорт производства и использование рабского труда коррелирует всякий раз, когда речь заходит о колониях юга. Цена на рынке рабов определялась в основном спросом в Вест-Индии и предложением в Африке Поэтому в период 1720-1800 гг., цены на рабов в среднеатлантических и южных колониях в долгосрочной перспективе были такими же, как в Вест-Индии. В краткосрочной перспективе всплески спроса на рабочую силу поднимали местные цены, увеличивая объемы импорта, которые в конечном счете цену снижал $^{28}$.

Таким образом, можно сделать ряд выводов относительно экономико-демографической ситуации в американских колониях. Американские колонии демонстрировали относительно высокий уровень заработка, сопоставимый с заработком трудящихся Великобритании. Колониальная экономика, быстро развиваясь, показала спецификацию регионов северных колоний, колоний средней Атлантики и колоний американского юга. Данная спецификация учитывала стоимость земельной собственности и выражалась как в ориентации населения на развитие мелких фермерских хозяйств, так и на формирование крупных сельскохозяйственных производств на плантациях. Таким образом формировался американский рынок труда, привлекавший как свободных переселенцев, так и наемных рабочих, а также определивший политику ввоза в колонии несвободной рабочей силы. Исходя из этих обстоятельств, рынок труда американских колоний являлся одним из факторов определявших и контролировавших внутреннюю и внешнюю трудовую миграцию.

\section{Jumepamypa / References}

Acemoglu D., Johnson S., Robinson J. Reversal of Fortune: Geography and Institutions in the Making of the Modern World Income Distribution // Quarterly Journal of Economics, 2002, № 117 (4). P. 1231-1294.

Allen R., Murphy T. Schneider E. The Colonial Origins of the Divergence in the Americas: A Labor Market Approach // Journal of Economic History, 2012, № 72 (4). P. 863-894.

Bjork G.C. The Weaning of the American Economy: Independence, Market Changes, and Economic Development // Journal of Economic History, 1964, № 24 (4). P. 541-560.

Egnal M. New World Economies: The Growth of the Thirteen Colonies and Early Canada. New York, 1998.

Galenson D. The Rise and Fall of Indentured Servitude in the Americas: An Economic Analysis // Journal of Economic History, 1984, № 44 (1). P. 1-26.

Galenson D. White Servitude in Colonial America: An Economic Analysis. Cambridge, 1981.

Grubb F. Redemptioner Immigration to Pennsylvania: Evidence on Contract Choice and Profitability // Journal of Economic History, 1986, № 46 (2). P. 407-418.

Grubb F. The Incidence of Servitude in Trans-Atlantic Migration, 1771-1804 // Explorations in Economic History, 1985, № 22 (3). P. 316-339.

Jones A.H. Wealth of a Nation to Be: The American Colonies on the Eve of the Revolution. New York, 1980.

Lindert P.H., Williamson J.G. American Incomes Before and After the Revolution // Journal of Economic History, 2013, 73 (3). P. 725-765.

Lindert P.H., Williamson J.G. Unequal Gains: American Growth and Inequality since 1700. Princeton, 2016.

Lindert P.H., Williamson J.G. American Colonial Incomes, 1650-1774 // Economic History Review, 2016, № 69 (1). P. 54-77.

Main G.L., Main J.T. Economic Growth and the Standard of Living in Southern New England, 1640-1774 // Journal of Economic History, 1988, № 48 (3). P. 27-46.

1985. № 22 (3). P. 316-339.

${ }^{28}$ Wicker E. Colonial Monetary Standards Contrasted: Evidence from the Seven Years' War // Journal of Economic History. 1985. № 45. P. 869-884 
McCusker J., Menard R. The Economy of British America, 1607-1789. Chapel Hill, NC., 1985 Mancall P.C., Weiss T. Was Economic Growth Likely in Colonial British North America? // Journal of Economic History, 1999, 59 (1). P. 17-40.

Mancall P.C., Rosenbloom J.L., Weiss T. Slave Prices and the South Carolina Economy, 1722 to 1800 // Journal of Economic History, 2001, № 61 (3). P. 616-639.

Morgan E.S. The Labor Problem at Jamestown, 1607-1618 // American Historical Review, 1971, № 76 (3). P. 595-611.

Rosenbloom J.L., Weiss T. Economic Growth in the Mid Atlantic Region: Conjectural Estimates for 1720 to 1800 // Explorations in Economic History, 2014, № 51 (1). P. 41-59.

Weiss R. The Issue of Paper Money in the American Colonies, 1720-1774// Journal of Economic History, 1970, № 30. P. 770-785.

Weiss $T$. Review of Unequaly Gains: American Growth and Inequality since 1700, by Peter H. Lindert and Jeffry G. Williamson // Journal of Economic History, 2017, № 77 (3). P. 952-954.

West R.C. Money in the Colonial American Economy // Economic Inquiry, 1978, № 16. P. 1-15

Wicker E. Colonial Monetary Standards Contrasted: Evidence from the Seven Years' War // Journal of Economic History, 1985, № 45. P. 869-884.

Статья поступила в редакиию 10.07.2019 г. 